\title{
Hemiparasitic plants increase alpine plant richness and evenness but reduce arbuscular mycorrhizal fungal colonization in dominant plant species
}

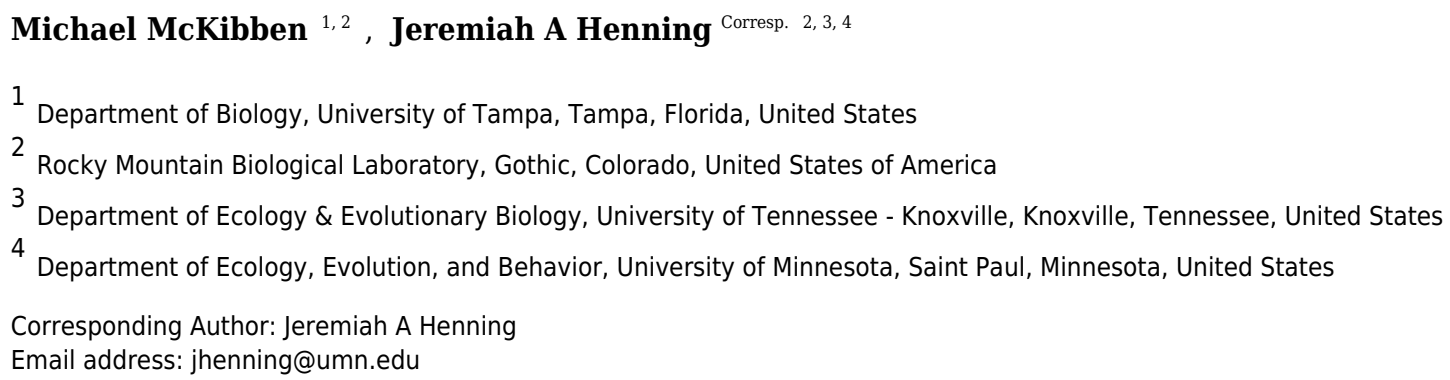

Hemiparasitic plants increase plant biodiversity by reducing the abundance of dominant plant species, allowing for the establishment of subordinate species. Hemiparasites reduce host resources by directly removing nutrients from hosts, competing for light and space, and may indirectly reduce host resources by disrupting plant associations with symbiotic root fungi, like arbuscular mycorrhizal fungi and dark-septate endophytes. Here we explored how a generalist hemiparasite, Castilleja,influences plant richness, evenness, community composition, and mycorrhizal colonization patterns across a $\sim 1000 \mathrm{~m}$ elevational gradient in the North American Rocky Mountains. We hypothesized that the presence of Castillejawould be associated with increased plant richness and evenness, shaping plant community composition, and would reduce mycorrhizal colonization within dominant plant taxa. However, the magnitude of the effects would be contingent upon climate contexts i.e.elevation. Overall, we found that the presence of Castillejawas associated with an $11 \%$ increase in plant richness and a $5 \%$ increase in plant evenness, regardless of elevation. However, we found that the presence ofCastillejainfluenced plant composition at only two of the five sites and at the remaining three of five sites, plot pairing was the only predictor that influenced composition. Additionally, we found that the presence of Castillejareduced mycorrhizal fungal colonization within dominant plant species by $\sim 20 \%$, regardless of elevation. Taken together, our results suggest that hemiparasites regulate plant diversity, evenness, and interactions with mycorrhizal fungi independent of abiotic and biotic contexts occurring at the site, although overall effect on community composition is likely driven by site-level factors. 
1 Hemiparasitic plants increase alpine plant richness and evenness but reduce arbuscular

2 mycorrhizal fungal colonization in dominant plant species

3

4 Michael McKibben ${ }^{1,2, ~ J e r e m i a h ~ A . ~ H e n n i n g ~} 2,3,4 *$

5

6

$7{ }^{1}$ Department of Biology, University of Tampa, 401 West Kennedy Blvd., Tampa, FL 33606

$8 \quad 2$ Rocky Mountain Biological Laboratory, P.O. Box 519, Crested Butte, CO 81224

$9{ }^{3}$ Ecology and Evolutionary Biology, University of Tennessee, 569 Dabney Hall, Knoxville, TN

1037996.

$11{ }^{4}$ Ecology, Evolution, and Behavior, University of Minnesota, 140 Gortner Laboratory, 1479

12 Gortner Avenue, Saint Paul, MN 55108

13

14

15 *jhenning@umn.edu

16 Michael.McKibben@spartans.ut.edu

17 fax: 1-612-625-5700

18

19 Running title: Hemiparasites increase plant diversity and reduce mycorrhizal colonization 


\section{Abstract (249 words)}

Hemiparasitic plants increase plant biodiversity by reducing the abundance of dominant

22 plant species, allowing for the establishment of subordinate species. Hemiparasites reduce host

23 resources by directly removing nutrients from hosts, competing for light and space, and may

24 indirectly reduce host resources by disrupting plant associations with symbiotic root fungi, like

25 arbuscular mycorrhizal fungi and dark-septate endophytes. Here we explored how a generalist

26 hemiparasite, Castilleja, influences plant richness, evenness, community composition, and

27 mycorrhizal colonization patterns across a 1000m elevational gradient in the North American

28 Rocky Mountains. We hypothesized that the presence of Castilleja would be associated with

29 increased plant richness and evenness, shaping plant community composition, and would reduce

30 mycorrhizal colonization within dominant plant taxa. However, the magnitude of the effects

31 would be contingent upon climate contexts i.e. elevation. Overall, we found that the presence of

32 Castilleja was associated with an $11 \%$ increase in plant richness and a 5\% increase in plant

33 evenness, regardless of elevation. However, we found that the presence of Castilleja influenced

34 plant composition at only two of the five sites and at the remaining three of five sites, plot

35 pairing was the only predictor that influenced composition. Additionally, we found that the

36 presence of Castilleja reduced mycorrhizal fungal colonization within dominant plant species by

$37 \sim 20 \%$, regardless of elevation. Taken together, our results suggest that hemiparasites regulate

38 plant diversity, evenness, and interactions with mycorrhizal fungi independent of abiotic and

39 biotic contexts occurring at the site, although overall effect on community composition is likely

40 driven by site-level factors. 


\section{Introduction}

Root hemiparasitic plants regulate plant community composition and ecosystem function

44

45

by reducing the abundance of dominant plant species, increasing co-existence of subordinate species, resulting in greater plant evenness (Davies et al. 1997; Press \& Phoenix 2005; Bardgett et al. 2006; Westbury et al. 2006; Reed 2012). However, see (Press \& Phoenix 2005; Westbury \& Dunnett 2007) for examples that counter this general pattern. Hemiparasites range from host specialists to complete generalists, but typically impact dominant plant species to a greater degree compared to lower abundance plant taxa (Davies et al. 1997; Westbury et al. 2006; Reed, 2012). However, generalist hemiparasites can have taxa specific effects independent of dominance patterns (Adler 2003; Demey et al. 2015). Hemiparasites directly reduce host plant biomass by parasitizing carbon and nutrients from the host through specialized structures called haustoria (Adler 2000; Salonen et al. 2001). Although, hemiparasites parasitize resources from their hosts, they are not wholly reliant on hosts for carbon and nutrient resources and fix carbon via photosynthesis and can obtain soil resources through absorptive roots (Ducharme \& Ehleringer 1996; Press \& Phoenix 2005). As a result, hemiparasites impact hosts by directly parasitizing host resources as well as competing for light and nutrients (Press \& Phoenix 2005). Additionally, hemiparasite associations with root-associated fungal communities like arbuscular mycorrhizal fungi (AMF) and dark septate endophytes (DSE) (Davies \& Graves 1998, Li \& Guan 2008) may provide an additional pathway for hemiparasites to acquire resources and compete with surrounding plant taxa.

Hemiparasite interactions with AMF and DSE may regulate or exacerbate parasitic effects of hemiparasites on plant communities (Gworgwor \& Weber 2003; Lendzemo et al. 2007; Bouwmeester et al. 2007; Li et al. 2012). AMF and DSE are ubiquitous across most ecosystems 
65 globally and provide nutrient resources to plant hosts in return for plant-derived carbon, leading

66 to the promotion of plant growth (Smith \& Read 2008; Mandyam, \& Jumpponen, 2014; Vergara

67 et al. 2017; Jumpponen et al. 2017). Hemiparasites may interact with AMF and DSE in a number

68 of ways. For instance, hemiparasites may benefit from a host plant's association with AMF and

69 DSE by indirectly accessing excess resources through the plant host, directly associating with the

70 common mycorrhizal network, or by capitalizing on plant-mycorrhizal signaling pathways to

71 colonize host roots (Davies and Graves 1998; Bouwmeester et al. 2007; Stein et al. 2009; De

72 Vega et al. 2010). If hemiparasites are superior competitors for host carbon resources, the

73 reduction in available carbon resources may lead to feedbacks between plant hosts and fungal

74 symbionts (Stewart \& Press 1990; Davies and Graves 1998; \& Phoenix 2005). Conversely,

75 plants may allocate more carbon resources to mycorrhizal fungi to increase nutrient access,

76 offsetting hemiparasite effects. However, the effect of hemiparasites on AMF and DSE carbon

77 allocation has not been directly tested. Conversely, AMF can inhibit the germination of

78 hemiparasite seeds and the attachment of hemiparasites on host plants, reducing the effect of

79 hemiparasites on host plants (Gworgwor \& Weber 2003; Lendzemo et al. 2007; Li et al. 2012).

80 Thus, the interaction among hemiparasites, AMF, DSE, and plant hosts will likely have

81 cascading effects on plant community diversity and composition, however the impact of

82 hemiparasites on AMF and DSE remains a significant knowledge gap.

83 Environmental contexts shape the composition and function of plant and fungal

84 communities (Callaway at al. 2002; Kivlin et al. 2011; Sundqvist et al. 2013; Jumpponen et al.

85 2017). Because hemiparasites influence plant community richness, evenness, and community

86 composition, it is likely that environmental contexts may regulate the effect of hemiparasites on

87 plant-fungal interactions (Marx et al. 1970; Press \& Phoenix 2005; Pennings \& Callaway 1996; 
88 2002). For example, in low productive ecosystems, hemiparasites typically have a stronger

89 influence on plant diversity and community composition because light competition with

90 surrounding plants is low (Matthies \& Egli 1999; Pennings \& Callaway 2002; Press \& Phoenix

91 2005; Těšitel et al. 2011; 2018). However, light competition in more productive ecosystems may

92 outweigh negative parasitic effects, reducing the effect of hemiparasites (Matthies \& Egli 1999;

93 Pennings \& Callaway 2002; Press \& Phoenix 2005; Těšitel et al. 2011; 2018). Additionally, it

94 has been hypothesized that hemiparasite effects on plant evenness and the promotion of

95 subordinate species should be greatest in areas with high competitive asynchronies among taxa

96 (Pennings \& Callaway 1996; Press \& Phoenix 2005). Thus, site-level abiotic and biotic factors

97 likely regulate the effects of hemiparasites on plant community composition and associations

98 with fungi.

99 Elevational gradients have a long history of usage to understand how biotic and abiotic

100 contexts shape species interactions, community composition, and ecosystem function

101 (MacArthur 1972; Callaway et al. 2002; Sundqvist et al. 2013; Read et al. 2017). Moving from

102 low to high elevation, abiotic properties like: temperature, precipitation, $\mathrm{pH}$, nutrient availability

103 and biotic factors like: plant taxa present, herbivore abundance, symbiont abundance shift while

104 often maintaining a similar disturbance history, soil parent material, and regional species pool

105 (reviewed in Körner 2007; Sundqvist et al. 2013). Together, biotic and abiotic factors shape the

106 outcome of species interactions (Callaway et al. 2002) and productivity (Whittaker et al. 1974;

107 Sundqvist et al. 2013) from low to high elevation. Across many elevational gradients, low

108 elevation soil fungal communities are dominated by host carbon-reliant AMF communities,

109 while high elevation ecosystems are often dominated by less host carbon-reliant DSE and ericoid

110 mycorrhizal fungi are more abundant relative to AMF (Haselwandter \& Read 1980; Schmidt et 
111 al. 2008). Thus, the effect of hemiparasites on plant diversity, community composition, and soil

112 fungal communities may shift across an elevational gradient, with effects on plant diversity and

113 fungal colonization exacerbated at lower elevation communities (Choler et al. 2001; Bardgett et

114 al. 2006; Reed 2012).

115 In the North American Rocky Mountains hemiparasites in the genus Castilleja

116 (Orobranchaceae) commonly occur in a wide-variety of montane ecotones (Hersch \& Roy,

117 2007). Castilleja, in this region, are perennial, generalist hemiparasites (Sweatt 1997; Adler

118 2003), that receive up to $40 \%$ of their carbon from plant hosts (Ducharme \& Ehleringer 1996).

119 Castilleja parasitize a wide variety of host plants, often increase plant community evenness, and

120 increase nitrogen cycling in nutrient poor soil (Ducharme \& Ehleringer 1996; Adler 2003; Reed

121 2012; Spasojevic \& Suding 2012). Across an elevational gradient near Gothic, Colorado, USA,

122 three species of Castilleja, C. angustifolia $(2,480-2,740 \mathrm{~m})$, C. miniata $(3,392 \mathrm{~m})$, and $C$.

123 sulphurea $(3200-3460 \mathrm{~m})$ are distributed in different elevational clines. Here, we measured

124 how the presence of Castilleja was related to: 1) plant richness and evenness of the surrounding

125 plant community, 2) the presence of Castilleja would alter community composition, and 3) the

126 presence of Castilleja would reduce dominant plant associations with AMF and DSE at 5 sites

127 along a $\sim 1000 \mathrm{~m}$ pre-established elevational gradient (Read et al. 2017) near Gothic, Colorado,

128 USA. We hypothesized that: 1) the presence of Castilleja would increase plant richness and

129 evenness, 2) which would re-shape community composition and that 3) Castilleja would reduce

130 the colonization of host carbon reliant AMF while increasing colonization of less carbon reliant

131 DSE in the roots of the dominant plant species. However, 4) the effects of Castilleja on plant and

132 fungal communities would be contingent on climate contexts, with stronger Castilleja effects at

133 low elevation, relative to higher elevation sites (increasing abiotic stress). 
135 Methods

136

137 Study Site

138 We utilized pre-existing sites along an elevational gradient that spanned from $2480 \mathrm{~m}$ to

$1393460 \mathrm{~m}(\sim 1000 \mathrm{~m})$ near Gothic, CO, USA (Read et al. 2017, Table 1). The sites are located on

140 USDA Forest Service land and are covered under Forest Service Special Use Permit

141 \#GUN1120.The gradient site receives about 439 to $668 \mathrm{~mm} \mathrm{yr}^{-1}$ of precipitation and has a mean

142 annual temperature of -1.6 to $1.5^{\circ} \mathrm{C}$ (Hijmans et al., 2005; Read et al. 2017; Table 1).

143 Additionally, nutrient availability shifts across the gradient, with high elevation sites having

144 more available phosphorus but lower available nitrogen relative to low elevation sites (Read et

145 al. 2017). Plant diversity is highest at middle elevation sites, while plant community composition

146 transitions from a sagebrush steppe at low elevation to montane meadows at high elevation

147 (Read et al. 2017).

148

149 Plant Community Sampling

150 At each elevation, we identified all Castilleja present within a $20 \mathrm{~m} \times 20 \mathrm{~m}$ area. Next, we

151 haphazardly-selected 10 Castilleja individuals of similar size and identified an adjacent

152 "Castilleja free" area that was located within $2 \mathrm{~m}$ distance from our focal Castilleja, but

153 contained no Castilleja within a $1.5 \mathrm{~m}$ diameter around the centroid. Thus, we sampled 100 total

154 plots $(10$ plots $\times 2$ Castilleja treatments $\times 5$ elevations $)$. From our sampling design, we were

155 unable to determine if plots were truly absent of Castilleja influence, as shallow-rooted

156 Castilleja can infect across a semi-broad spatial area (Ducharme \& Ehleringer 1996). Logistical 
157 constraints of the pre-existing elevational gradient and the observational focus of our study

158 prevented us from removing Castilleja individuals, which would have provided a more direct

159 measurement of Castilleja effects on plant community composition and ecosystem function.

160 To measure plant community composition, we identified all plant species present within a

$1610.5 \times 0.5 \mathrm{~m}$ quadrat in each plot. Plant community composition was measured in the Castilleja

162 present plots, but placing the focal Castilleja in the center of our quadrat and Castilleja-free

163 surveys were conducted by placing the quadrat in the center of the Castilleja-free area to

164 maximize the distance from all surrounding Castilleja plants. Next, we visually estimated the

165 cover of each species present in the quadrat. We estimated percent coverage to the nearest $1 \%$

166 for species $<20 \%$ and the nearest $5 \%$ for species $>20 \%$ coverage. We also estimated the amount

167 of bare ground and rock within each plot.

168

\section{Root sampling}

$170 \quad$ From our cover data, we identified the most abundant plant species that occurred in all 20

171 plots at each elevation to sample for fungal colonization. At 1 of the 5 sites $(2,480 \mathrm{~m})$, our

172 sampled plant species (Balsamorhiza sagittata) was also the dominant taxa, however at 4 of the 5

173 sites, we sampled either the $2^{\text {nd }}$ or $3^{\text {rd }}$ most abundant taxa, as the dominant taxa did not occur in

174 all 20 plots. We collected a single $2.5 \times 15 \mathrm{~cm}$ core from our focal individual to measure the

175 colonization of AMF and DSE. A single focal plant (Table 1) was haphazardly selected near the

176 center of each plot (10 plots $\times 2$ Castilleja treatments $\times 5$ elevations $=100$ total soil cores $).$ We

177 transported the soil cores back to the Rocky Mountain Biological Laboratory on ice and stored

178 them at $4^{\circ} \mathrm{C}$ in lab until being processed within 24 hours. Next, we extracted live roots from the

179 core using a $0.5 \mathrm{~mm}$ mesh sieve and placed roots in Fisher brand Histosette II tissue cassettes 
180 (Catalog \#1000965, Thermo Fisher Scientific, Waltham, MA, USA). Tissue cassettes were then

181 placed in deionized water to remove any remaining soil. Next, we cleared pigment from roots in

182 a $10 \%$ potassium hydroxide $(\mathrm{KOH})$ solution, acidified root samples in a $2 \%$ hydrochloric acid

$183(\mathrm{HCl})$ solution, and then stained roots in a $0.01 \%$ trypan blue solution (Koske \& Gemma 1989).

184 We then mounted roots on microscope slides using PVLG (polyvinyl lactic acid glycerol) glue

185 (INVAM 2017) and slides were oven dried at $50^{\circ} \mathrm{C}$ for 48 hours. We removed two root samples

186 (Castilleja present plant 5 and 8) from our 3,200m elevation site because of low root biomass.

187 Next, we quantified the presence of AMF hyphae, DSE hyphae, as well as AMF vesicles,

188 arbuscules, coils, and spores, DSE microsclerotia, and any potential pathogens, of at least 50 root

189 intersections per slide, using the magnified grid-line intercept method (McGonigle et al. 1990).

190 Finally, we calculated percent colonization of AMF, DSE, and any structures and potential

191 pathogens by dividing the number of positive observations by the total number of root

192 intersections observed.

193

194 Statistical Analysis

195 All analyses were conducted in R (R Development Core Team, 2008) and RStudio

196 (RStudio Support Team, 2015), with packages cited within. To test for differences in plant

197 richness, evenness, and community composition independent of the contribution of Castilleja we

198 removed the Castilleja cover from all analyses. However, Castilleja cover is located in Table 1.

199 We calculated species richness using the specnumber function in the "vegan" package (Oksanen

200 et al. 2017) and species evenness as the probability of interspecific encounter (PIE, Simpson's

201 Evenness) $\left(\right.$ Hurlbert 1971) as: $\mathrm{PIE}=\mathrm{N} /(\mathrm{N}-1) \times\left(1-\sum \mathrm{p}_{i}^{2}\right)$, where $\mathrm{N}=$ total number of individuals,

202 and $\mathrm{p}_{i}=$ is the relative abundance of species $i$. within each plot using the calcPIE function in the 
203 "mobr" package (McGlinn et al. 2018). We chose to calculate PIE as our evenness measurement

204 because of its independence from sample size when comparing across elevation sites (Chase \&

205 Knight 2013). We tested for differences in plant richness and evenness between plots associated

206 with the presence of Castilleja across sites by constructing linear mixed-effect models with

207 elevational site, Castilleja presence (absent or present), and their interaction as fixed factors

208 using the nlme package (Pinheiro et al. 2014). Within each mixed model, we allowed the

209 intercept to vary by plot pairings (random effect). Next, we constructed mixed effect models with

210 and without fixed factors (elevation and Castilleja presence) and compared AIC scores to

211 determine if adding each fixed factor improved model fit. Next, we calculated the deviance and

212 compared the inclusion of each factor with a likelihood ratio test using the Anova function ("car"

213 package, Fox \& Weisberg, 2011).

214 To test whether the presence of Castilleja was associated with changes in plant

215 community composition, we performed a PERMANOVA using the adonis function in the vegan

216 package (Oksanen et al. 2017) with Castilleja presence, elevation, and plot pairing as predictors.

217 To separate the effects of Castilleja presence on abundance shifts among dominant taxa versus

218 changes in taxa gains and losses, we performed PERMANOVAs using abundance-weighted

219 Bray-Curtis distances as well as presence-absence data using Jaccard's distance. During our

220 initial PERMANOVA fitting across all sites (Table S2), we observed significant interaction

221 terms within both elevation $\times$ Castilleja presence $\left(F_{(1,99)}=2.532, p=0.01\right)$ and elevation $\times$ plot

222 pairing $\left(F_{(1,99)}=13.48, p=0.01\right)$, which suggested that effect of Castilleja presence on plant

223 community composition differed by site. To explore when and where Castilleja was associated

224 with plant community composition, we conducted separate PERMANOVAs for each elevation. 
225 Within our site level PERMOANOVAs, we included Castilleja presence, plot pairing, and their

226 interaction as predictor variables.

227 To visualize the results of our PERMANOVAs, we performed non-metric

228 multidimensional (nMDS) scaling based on Bray-Curtis distances using the metaMDS function

229 in the vegan package (Oksanen et al. 2017) for each elevational site.

230 Finally, we compared fungal colonization patterns within the dominant plant species with

231 mixed effect models as described above, with Castilleja presence/absence, elevational site and

232 the interaction between Castilleja presence and elevation as predictor variables. For fungal

233 mixed models, we constructed AMF and DSE models separately. Structures of AMF and DSE

234 (vesicles, arbuscules, coils, spores, microsclerotia) were extremely rare within our samples,

235 therefore we present only AMF and DSE hyphal colonization data.

236

237 Results

238 Castilleja association with plant richness and evenness

239 Overall, we found that the presence of Castilleja and elevation were retained within our

240 best models to predict plant richness and evenness (Table S1). Taken as a whole, we found that

241 the presence of Castilleja was associated with an increase in plant richness of $11 \%\left(\chi^{2}=52.360\right.$,

$242 \mathrm{p}<0.0001$, Table 2), and an increase in plant evenness of 5\% $\left(\chi^{2}=6.805, \mathrm{p}=0.009\right.$, Table 2).

243 As expected, elevation significantly impacted plant richness and evenness, with the highest plant

244 species richness and evenness values observed at the middle elevation sites ( $3200 \mathrm{~m}$ : richness $\mu$

$245=11.8$, evenness $\mu=0.835 ; 3392 \mathrm{~m}$ : richness $\mu=11.2$, evenness $\mu=8.46)$ (Table 2)(Fig 1).

246 Surprisingly, we observed no significant interaction terms between Castilleja presence and plant

247 richness or evenness (Table 2). 


\section{Castilleja association with plant community composition changes}

Overall, we found that elevation was the best predictor of plant community composition change, accounting for $30 \%$ of the data variation in community composition (Table S2). Using abundance-weighted measures, Castilleja presence was associated with a significant $(p=0.01)$, but weak effect $\left(\mathrm{R}^{2}=0.021\right)$ on overall plant community composition (Table S2). Site-level heterogeneity (plot pairings) explained an additional 9\% of data variation across plant community composition.

At the site level, we found that the presence of Castilleja was associated with plant composition shifts in abundance-weighted (Bray-Curtis distance) at two $(2,740 \mathrm{~m}$ and 3,200m ) of the five elevation sites (Table 3; Fig 2). At 2,740m, we observed higher abundance of Adenolinum lewisii, Phacelia sericea, Antennaria rosea and reduced abundance of shrub species Artemisia tridentate and Symphoricarpos rotundifolia, and forb Delphinium nuttallianum when Castilleja was present (Fig 2). At 3,200m, we observed reduced cover of invasive species Bromopsis inermis, when Castilleja was present (Fig 2). At three of the five sites $(2,480 \mathrm{~m}$, $3,392 \mathrm{~m}$, and 3,460m), we observed a significant relationship of plot pairing, suggesting that spatial heterogeneity in plant community composition may cloud our ability to observe the effect of Castilleja on community composition. Unlike our abundance-weighted results, we found no effect of Castilleja and only weak effects of plot pairings on plant community composition when

267 sites were compared using Jaccard's index (Table S3). 
271 colonization at each site by $20 \%$ (Table 2, Fig 3 ) and was the only factor retained within our best

272 fit model (Table S1). At our four lowest elevation sites Castilleja presence was correlated with a

273 reduction in AMF colonization in Balsamorhiza sagittata (2480 m), Chrysothamnus viscidiflorus

274 (2740 m), Viola adunca (3200 m), Ligusticum porteri (3392 m), and at our highest (3460 m)

275 elevation site, Castilleja presence was correlated to a reduction in ericoid mycorrhizae

276 colonization within Arctostaphylos uva-ursi. We found that climate contexts had no impact on

277 Castilleja effects, as elevation was not retained within our best-fit model for mycorrhizal

278 colonization (Table S1). Surprisingly, we found that Castilleja presence was not related to DSE

279 colonization and only elevation was retained within the best fit model predicting DSE

280 colonization. Overall, we found that DSE colonization was highest $(\mu=51.9 \%)$ at our high

281 elevation site $(3,460 \mathrm{~m})$, and colonization rates were similar at the four other elevations, ranging 282 from 27-33\% (Table 2, Fig 3).

283

284 Discussion

285 Castilleja increases plant richness and evenness

286 Overall, we found the presence of Castilleja was associated with an $11 \%$ increase in plant

287 richness and a 5\% increase in plant evenness. Our results are in line with several studies that 288 have found increased plant richness and evenness with the presence hemiparasites (Davies et al. 289 1997; Press \& Phoenix 2005; Bardgett et al. 2006; Westbury et al. 2006; Reed 2012), although 290 this result can be contingent on hemiparasite identity and the identity of the surrounding plant 291 community (Press \& Pheonix 2005; Westbury \& Dunnett 2007). Interestingly, we found the 292 effect of Castilleja associated with plant richness and evenness did not differ by site, suggesting 
293 in this system Castilleja effects may be consistent despite the shifting biotic and abiotic contexts

294 along the elevational gradient. Background plant richness and evenness shifted across the

295 elevational gradient, displaying the characteristic unimodal pattern with highest richness and

296 evenness at middle elevations. Additionally, the species of Castilleja present differed by

297 elevation, with $C$. angustifolia present at 2,480 $\mathrm{m}$ and 2,740 $\mathrm{m}$, C. miniata at 3,392 $\mathrm{m}$, and $C$.

298 sulphurea at $3200 \mathrm{~m}, 3,392 \mathrm{~m}$, and $3460 \mathrm{~m}$.

299

300 Castilleja has inconsistent effects on plant community composition

301 The presence of Castilleja was associated with a significant, but weak, effect on overall

302 plant community composition across the elevational gradient. However, site-level analyses

303 revealed that the effect of Castilleja on abundance-weighted plant community composition

304 differed by site. For example, at two of our middle elevation sites $(2,740 \mathrm{~m}$ and $3,200 \mathrm{~m})$, the

305 presence of Castilleja was the strongest predictor of plant community composition. The presence

306 of Castilleja was correlated with a reduction in aboveground cover of shrub species Artemisia

307 tridentata and Symphoricarpos rotundifolia at 2,740m and invasive grass Bromopsis inermis at

$3083,200 \mathrm{~m}$. The reduction of shrub and grass taxa was matched with an increase in low abundant

309 forb taxa: Adenolinum lewisii, Phacelia sericea, and Antennaria rosea. However, it is important

310 to note the nature of our study did not allow us determine which hosts Castilleja were

311 parasitizing, how much carbon was being parasitized from hosts, or the long-term dynamics of

312 Castilleja in an ecosystem comprised mostly of long-lived perennial plant taxa. In a previous

313 study by Ducharme and Ehlerginer (1996), authors found Castilleja received $\sim 40 \%$ of its carbon

314 from critical host Artemisia tridentata. However, Castilleja had no effect on the photosynthetic

315 rates or water potentials of Artemisia over a two-year period. Thus, it is unclear how detrimental 
316 Castilleja is for host production and survival (Ducharme \& Ehlerginer 1996; but see Reid et al.

3171994 and Bowie \& Ward 2004).

318 The association of Castilleja presence on plant community composition was only

319 apparent when we compared plant community composition using abundance-weighted Bray-

320 Curtis distance metrics. When we compared plant community composition using

321 presence/absence data we found no association of Castilleja presence. This suggests that the

322 association of Castilleja is primarily driven by abundance changes among dominant plant taxa

323 and less by taxa gains and losses. Taken together, our results align with previous studies

324 demonstrating that few hemiparasites reduce host resources enough to cause mortality, but can

325 reduce host growth rate allowing for the establishment of subordinate taxa (Reid et al. 1994;

326 Watson 2009).

327 Although our study is not a direct test of the effect of Castilleja on plant community

328 composition, our results align with previous direct, manipulative hemiparasite removal and

329 addition experiments that report a strong negative effect of hemiparasites on dominant taxa

330 abundance with an overall increase in plant diversity, especially with forb taxa (Pennings \&

331 Callaway 1996; Davies et al. 1997; Press 1998; Press \& Pheonix 2005; Bardgett et al. 2006;

332 Těšitel et al. 2015; 2018). For instance, sowing of hemiparasite Rhinanthus into a Calamagrostis

333 invaded grassland reduced Calamagrostis cover from $\sim 45 \%$ to $\sim 2 \%$ within two growing seasons

334 (Těšitel et al. 2018). Overall, plant diversity increased to compensate for the reduction in

335 Calamagrostis biomass and cover, although authors found that Rhianthus had inconsistent

336 effects on overall plant community composition. Taken together, this suggests that hemiparasite

337 effects on overall plant community composition are likely driven by the identity of the

338 surrounding plant species, competitive ability of these taxa, and abundance levels of those taxa 
339 (Press \& Phoenix 2005; Watson 2009; Těšitel et al. 2018). To confirm previous findings, a

340 direct test manipulating both plant community composition and the presence of hemiparasites

341 needs to be performed.

342

343 Site-level spatial heterogeneity was a strong driver of plant community composition

344 At three of the five sites $(2,480 \mathrm{~m}, 3,392 \mathrm{~m}, 3,460 \mathrm{~m})$, plot pairing was the strongest

345 predictor of plant community composition explaining $\sim 13 \%, 18 \%$, and $13 \%$ respectively, of the

346 data variation in community composition. At each of these three sites, the presence of Castilleja

347 had no effect on plant community composition, suggesting that site-level spatial heterogeneity

348 obscures our ability to detect changes in community composition mediated by hemiparasites.

349 This was surprising because we observed a similar increase in plant richness and plant evenness

350 between plot pairings at all five sites. The overall richness and evenness effects, but limited

351 compositional effects likely reflects the generalist hemiparasite life history of Castilleja

352 (Ducharme \& Ehleringer 1996; Adler 2003; Spasojevic \& Suding 2012). Additionally, the effect

353 of plot pairing was stronger using abundance-mediated measures community composition (Bray-

354 Curtis distance), compared to presence-absence (Jaccard's distance). With the exception of our

355 low elevation site, we observed no effect of plot pairing on plant community composition using

356 Jaccard's distance metrics. This suggests that at each site, differences in community composition

357 were driven by abundance differences in taxa plot to plot, and less by taxa turnover among plots.

359 Hemiparasitic plants shape abundant plant interactions with mycorrhizal fungi

360 Overall, we found that the presence of Castilleja was associated with a reduction in AMF

361 colonization by $18 \%$ and ericoid mycorrhizal fungi (ERM) by $17 \%$. However, we found no 
362 effect of Castilleja presence on DSE colonization within focal taxa roots. We found that

363 Castilleja reduced mycorrhizal colonization similarly across elevation sites even though the

364 overall rate of colonization differed by elevation, suggesting a ubiquitous pattern independent of

365 biotic and abiotic contexts, counter to our expectations. However, our results provide an indirect

366 test of the effect of Castilleja on mycorrhizal colonization because we did not confirm if sampled

367 plants were actively parasitized by Castilleja. Additionally, we were unable to determine if every

368 single root we quantified colonization was from the target individual. However, even with the

369 indirect measure and the uncertainty of host identity, we still observed a consistent reduction in

370 mycorrhizal colonization when Castilleja was present.

371 Our results align with previous studies that observed a reduction in mycorrhizal fungal

372 colonization with hemiparasite colonization (Gehring \& Whitham 1992; Davies \& Graves 1998;

373 reviewed in Press \& Phoenix 2005). One potential explanation for the reduction in mycorrhizal

374 colonization is that hemiparasites outcompete mycorrhizal fungi for host carbon resources

375 (Gehring \& Whitham 1992; Davies \& Graves 1998; reviewed in Press \& Phoenix 2005).

376 Because AMF have a higher reliance on host-derived carbon resources relative to DSE and

377 ERM, competition with hemiparasites for host carbon may explain why we observed reduced

378 AMF colonization but no difference in DSE colonization (Caldwell et al. 2000; Jumpponen,

379 2001; Usuki \& Narisawa 2007; Knapp et al. 2018). Although at our high elevation site, we

380 observed reduced ERM colonization in Arctostaphylos uva-ursi even though ERM produce a

381 suite of carbon-degrading enzymes making them less reliant on plant-derived carbon (Read et al.

382 2004; Smith \& Read 2008; Averill et al. 2014). Future studies should directly test whether

383 hemiparasites reduce carbon allocation to mycorrhizal fungi and whether the differences in the 
384 reliance on host carbon resources will determine the response of fungal colonization to

385 hemiparasite presence.

386 Hemiparasites also directly associate with mycorrhizal fungi and DSE (Bouwmeester et

387 al. 2007; Li \& Guan 2008; Stein et al. 2009; Li et al. 2012). Associations with mycorrhizal fungi

388 and DSE may provide an additional mechanism for hemiparasites to access soil and plant-

389 derived resources (Li \& Guan 2008;), so it is unclear whether a reduction fungal colonization in

390 dominant plant species would be detrimental to hemiparasites. In a previous field census, we

391 found both AMF and DSE actively colonizing the roots of $C$. angustifolia, C. miniate, and $C$.

392 sulphurea across this elevational gradient (Henning unpublished data). However, we did not

393 measure fungal colonization rates of Castilleja in this study. Our results highlight an interesting

394 pattern, however further study is required to determine if interactions among hemiparasites,

395 mycorrhizal fungi, and plant hosts could cascade to influence plant community composition and 396 ecosystem function.

397

\section{Hemiparasite effects on plant diversity, plant community composition and mycorrhizal} colonization are independent of climate contexts

We sought to explore how climate contexts shape the impact of hemiparasites on plant

richness, evenness, community composition, and the relationship of dominant plant species with root symbionts. Although we found that the presence of Castilleja or elevation were always retained in the best fit models for plant richness, evenness, mycorrhizal colonization, and DSE,

404 we did not observe any significant interactions between the presence of Castilleja and elevation

405 for any response variable. This suggests that hemiparasites increase plant richness, increase plant 406 evenness and reduce mycorrhizal fungal colonization within dominant species independent of 
407 biotic and abiotic contexts. Our results are counter to several studies, which have found

408 hemiparasite effects are contingent on-site properties like: plant composition; nutrient

409 availability, soil moisture, mycorrhizal fungi present, plant productivity (Callaway \& Pennings

410 1998; Matthies \& Egli 1999; Stein et al. 2009; Těšitel et al. 2015; 2018). Thus, across a wide

411 array of ecosystems, hemiparasites may be critical for the maintenance of plant diversity and the

412 regulation of competitively dominant plant taxa.

\section{Conclusions}

415 Overall, we found that the presence of Castilleja was consistently associated with

416 increased richness and evenness within the plant community, while reducing colonization by

417 mycorrhizal fungi across a wide-spread elevational gradient. This suggests that the effect of

418 Castilleja on plant and fungal communities is consistent across climate contexts, the species of

419 Castilleja present, and differences in plant community composition, and underlying differences

420 in overall diversity, even if the overall effect of Castilleja on plant community composition was

421 inconsistent. Although our study was observational by design, our study provides testable

422 hypothesis to explore within future mechanistic experiments exploring the interaction between

423 hemiparasites, mycorrhizal fungi, and host plants, across climatic gradients.

\section{Acknowledgements}

425 We like to thank the staff of the Rocky Mountain Biological Laboratory (RMBL) for their

426 logistical. Additionally, we would like to acknowledge Quentin D. Read the mental and

427 emotional contributions for establishing and collecting background data from elevational sites in 428 collaboration with J.A.H. 


\section{Literature Cited}

430 Adler, L. S., (2003). Host species affects herbivory, pollination, and reproduction in experiments with parasitic Castilleja. Ecology, 84(8), 2083-2091. DOI: https://doi.org/10.1890/02-

432 $\underline{0542}$

433

Averill, C., Turner, B. L., and Finzi, A. C., (2014). Mycorrhiza-mediated competition between plants and decomposers drives soil carbon storage. Nature, 505(7484), 543. DOI: https://doi.org/10.1038/nature12901

Bardgett D. R., Smith S. R., Shiel S. R., Peacock S., Simkin M. J., Quirk H., and Hobbs J. P., (2006). Parasitic plants indirectly regulate below-ground properties in grassland ecosystems. Nature 439, no. 7079: 969-972. DOI: 10.1038/nature04197

Bouwmeester H. J., Roux C., Lopez-Raez J. A., and Becard G., (2007). Rhizosphere communication of plants, parasitic plants and AM fungi. Trends in plant science, 12(5), pp.224-230. DOI: $\underline{10.1016 / \mathrm{j} . t p l a n t s .2007 .03 .009}$

Bowie M., and Ward D., (2004) Water and nutrient status of the mistletoe Plicosepalus acaciae parasitic on isolated Negev Desert populations of Acacia raddiana differing in level of mortality. Journal of Arid Environments, 56, 487-508. DOI: https://doi.org/10.1016/S0140-1963(03)00067-3

Caldwell A. B., Jumpponen A., and Trappe M. J., (2000). Utilization of major detrital substrates by dark-septate, root endophytes. Mycologia: 230-232. DOI:10.2307/3761555

Callaway R. M., and Pennings S. C., (1998). Impact of a parasitic plant on the zonation of two salt marsh perennials. Oecologia 114: 100-105. DOI: 10.1007/s004420050425.

Callaway R. M., Brooker R. W., Choler P., Kikvidze Z., Lortie C. J., Michalet R., Paolini L., Pugnaire F.I., Newingham B., and Aschehoug, E. T., (2002). Positive interactions among 
452

453

454

455

456

457

458

459

460

461

462

463

464

465

466

467

468

469

470

471

472

473

alpine plants increase with stress. Nature 417:844-48. DOI:

https://doi.org/10.1038/nature00812

Chase J.M., Knight T.M., (2013). Scale-dependent effect sizes of ecological drivers on biodiversity: why standardized sampling is not enough. Ecology Letters: 16: 17-26. DOI: 10.1111/ele.12112.

Choler P., Michalet R., and Callaway R. M., (2001). Facilitation and Competition on Gradients in Alpine Plant Communities. Ecology 82, no. 12: 3295-308. DOI:10.2307/2680153.

Davies D. M., Graves J. D., Elias C. O., and Williams P. J., (1997). The impact of Rhinanthus spp. on sward productivity and composition: implications for the restoration of speciesrich grasslands. Biological Conservation, 82(1): 87-93. DOI: https://doi.org/10.1016/S0006-3207(97)00010-4

Davies D. M., and Graves J. D., (1998) Interactions between arbuscular mycorrhizal fungi and the hemiparasitic angiosperm Rhinanthus minor during co-infection of a host. New Phytologist 139, no. 3: 555-563. DOI: 10.1046/j.1469-8137.1998.00211.x

Demey, A., De Frenne, P. , Baeten, L., Verstraeten, G. , Hermy, M. , Boeckx, P. , Verheyen, K. and Pugnaire, F., (2015), The effects of hemiparasitic plant removal on community structure and seedling establishment in semi-natural grasslands. Journal of Vegetation Science, 26: 409-420. doi:10.1111/jvs.12262

Ducharme, L. A. and Ehleringer, J. R., (1996). Gas exchange, $\delta^{13} \mathrm{C}$, and heterotrophy for Castilleja linariifolia and Orhocarpus tomiei, facultative root hemiparasites on Artemisia tridentata. The Great Basin Naturalist, pp.333-340. Available at: https://www.jstor.org/stable/41712959 
474 Fox J., and Weisberg S., (2011). An $\{R\}$ Companion to Applied Regression, Second Edition.

475 Thousand Oaks CA: Sage.

476 Gehring, C. A., and Whitham, T. G., (1992). Reduced mycorrhizae on Juniperus monosperma

477

478

479

480

481

482

483

484

485

486

487

488

489

490

491

492

493

494

495

with mistletoe: the influence of environmental stress and tree gender on a plant parasite and a plant-fungal mutualism. Oecologia, 89(2), 298-303. DOI: https://doi.org/10.1007/BF00317231

Gworgwor, N. A., and Weber, H. C., (2003). Arbuscular mycorrhizal fungi-parasite-host interaction for the control of Striga hermonthica (Del.) Benth. in sorghum [Sorghum bicolor (L.) Moench]. Mycorrhiza, 13(5), pp.277-281. DOI: https://doi.org/10.1007/s00572-003-

Haselwandter, K. and Read, D. J., (1980). Fungal associations of roots of dominant and subdominant plants in high-alpine vegetation systems with special reference to mycorrhiza. Oecologia, 45(1), pp.57-62. DOI:

https://doi.org/10.1007/BF00346707

Hersch I. E., and Roy A. B., (2007). Context-dependent pollinator behavior: an explanation for patterns of hybridization among three species of Indian paintbrush. Evolution 61, no. 1: 111-124. DOI: $10.1111 / j .1558-5646.2007 .00009 . x$

Hijmans R. J., Cameron S. E., Parra J. L., Jones P. G., and Jarvis A., (2005). Very high resolution interpolated climate surfaces for global land areas. International Journal of Climatology 25: 1965-1978. DOI: 10.1002/joc.1276

Hurlbert, S. H., (1971) The nonconcept of species diversity: a critique and alternative parameters. Ecology 52, 577-586. DOI: https://doi.org/10.2307/1934145 
496 International culture collection of (Vesicular) Arbuscular Mycorrhizal fungi (INVAM). (2017).

497 https://invam.wvu.edu/methods/recipes, accessed July 20 2017.

498 Joshi J., Matthies D., and Schmid B. ,(2000). Root hemiparasites and plant diversity in

499 experimental grassland communities. Journal of Ecology 88, no. 4: 634-644. DOI:

$500 \quad$ https://doi.org/10.1046/j.1365-2745.2000.00487.x

501 Jumpponen A., (2001). Dark septate endophytes-are they mycorrhizal?. Mycorrhiza 11, no. 4: 207-211. DOI: https://doi.org/10.1007/s005720100112

503 Jumpponen, A., Herrera, J., Porras-Alfaro, A. and Rudgers, J., (2017). Biogeography of root-

504 associated fungal endophytes. In Biogeography of Mycorrhizal Symbiosis (pp. 195-222).

$505 \quad$ Springer, Cham.

506 Kivlin, S.N., Hawkes, C.V. and Treseder, K.K., (2011). Global diversity and distribution of 507 arbuscular mycorrhizal fungi. Soil Biology and Biochemistry, 43(11), pp.2294-2303.

508 Koske R. E., and Gemma J. N., (1989). A modified procedure for staining roots to detect VA

509 mycorrhizas. Mycological Research 92, no. 4: 486-488. DOI:

$510 \quad$ https://doi.org/10.1016/S0953-7562(89)80195-9

511 Knapp, D. G., Németh, J. B., Barry, K., Hainaut, M., Henrissat, B., Johnson, J., Kuo, A., Lim,

512 J.H.P., Lipzen, A., Nolan, M., Ohm, R. A., Tamás, L., Grigoriev, I.V., Spatafora, J. W.

513 Nagy, L.G., and Kovács, G.M.,(2018). Comparative genomics provides insights into the

514 lifestyle and reveals functional heterogeneity of dark septate endophytic fungi. Scientific

515 reports, 8(1), 6321. DOI: $\underline{\text { https://doi.org/10.1038/s41598-018-24686-4 }}$

516 Körner C., (2007). The use of 'altitude' in ecological research. Trends Ecol. Evol. 22:569-74

517 DOI: $\underline{\text { https://doi.org/10.1016/j.tree.2007.09.006 }}$ 
518 Lendzemo V. W., Kuyper T. W., Matusova R., Bouwmeester H. J., and Ast, A. V., (2007).

519 Colonization by arbuscular mycorrhizal fungi of sorghum leads to reduced germination

520 and subsequent attachment and emergence of Striga hermonthica. Plant signaling \&

521 behavior, 2(1), pp.58-62. DOI: https://doi.org/10.4161/psb.2.1.3884

522 Li A. R., and Guan K.Y., (2008) Arbuscular mycorrhizal fungi may serve as another nutrient

523

524

525

526

527

528

529

530

531

532

533

534

535

536

537

538

539 strategy for some hemiparasitic species of Pedicularis (Orobanchaceae). Mycorrhiza 18: 429. https://doi.org/10.1007/s00572-008-0196-Z

Li A. R., Smith S. E., Smith F. A., and Guan K.Y., (2012). Inoculation with arbuscular mycorrhizal fungi suppresses initiation of haustoria in the root hemiparasite Pedicularis tricolor. Annals of botany, 109(6), pp.1075-1080. DOI: https://doi.org/10.1093/aob/mcs028

MacArthur R. H., (1972). Geographical Ecology. Princeton, NJ: Princeton Univ. Press

Mandyam K., and Jumpponen A., (2014). Unraveling the dark septate endophyte functions: insights from the Arabidopsis model. Advances in Endophytic Research: 115-141. DOI: https://doi.org/10.1007/978-81-322-1575-2_6

Marx H. D., Bryan W. C., and Davey B. C., (1970). Influence of temperature on aseptic synthesis of ectomycorrhizae by Thelephora terrestris and Pisolithus tinctorius on loblolly pine. Forest Science 16, no. 4: 424-431. DOI: https://doi.org/10.1093/forestscience/16.4.424

Matthies D., and Egli P., (1999). Response of a root hemiparasite to elevated CO2 depends on host type and soil nutrients. Oecologia 120: 156-161. DOI: https://doi.org/10.1007/s004420050 
540 McGlinn D. J., Xiao X., May F., Blowes S., Chase J., Gotelli N., Knight T., McGill B., and

541 Purschke O., (2018) preprint. MoB (Measurement of Biodiversity): a method to separate

542 the scale-dependent effects of species abundance distribution, density, and aggregation on

543 diversity change. *bioRxiv*244103. doi: https://doi.org/10.1101/244103.

544 McGonigle T. P., Miller M. H., Evans D. G., Fairchild G. L., and Swan J. A., (1990). A new

545

546

547

548

549

550

551

552

553

554

555

556

557

558

559

560

561

562

method which gives an objective measure of colonization of roots by vesiculararbuscular mycorrhizal fungi." New Phytologist, 115, no. 3: 495-501. DOI: 10.1111/j.1469-8137.1990.tb00476.x

Oksanen J., Blanchet F. G., Friendly M., Kindt R., Legendre P., McGlinn D., Minchin R. P., O'Hara R. B., Simpson G. L., Solymos P., Stevens M. H., Szoecs E., and Wagner H., (2017). vegan: Community Ecology Package. R package version 2.4-3. https://CRAN.Rproject.org/package= $=$ vegan

Pennings S. C., and Callaway R. M., (1996). Impact of a parasitic plant on the structure and dynamics of salt marsh vegetation. Ecology, 77(5), pp.1410-1419. DOI: https://doi.org/10.2307/2265538

Pennings S. C., and Callaway R. M., (2002). Parasitic plants: parallels and contrasts with herbivores. Oecologia, 131(4), pp.479-489. DOI: https://doi.org/10.1007/s00442-0020923-7

Pinheiro .J, Bates D., DebRoy S., and Sarkar D., (2014). R Core Team (2014) nlme: linear and nonlinear mixed effects models. R package version 3.1-117. Available at $h \mathrm{ttp}: / / C R A N$. R-project. org/package $=$ nlme.

Press M. C., and Phoenix K. G., (2005). Impacts of parasitic plants on natural communities. New Phytologist 166, no. 3: 737-751. DOI: https://doi.org/10.1111/j.1469-8137.2005.01358.x 
563 Press M. C., (1998). Dracula or Robin Hood? A functional role for root hemiparasites in nutrient

564 poor ecosystems. Oikos 82: 609-611. DOI: 10.1007/s00442-010-1726-X

565 R Development Core. 2008. R: A language and environment for statistical computing. $R$

566 Foundation for Statistical Computing, Vienna, Austria. ISBN 3-900051-07-0 (2008).

567 Available at: http://www.R-project.org/.

568 RStudio Team (2015). RStudio: Integrated Development for R. RStudio, Inc., Boston, M.

569 Available at: http://www.rstudio.com/

570 Read Q. D., Henning J. A., and Sanders N. J., (2017). Intraspecific variation in traits reduces

571 ability of trait-based models to predict community structure. Journal of Vegetative

$572 \quad$ Science. DOI: $10.1111 /$ jvs.12555.

573 Read D. J., Leake J. R., and Perez-Moreno J. (2004). Mycorrhizal fungi as drivers of ecosystem processes in heathland and boreal forest biomes. Canadian Journal of Botany 82: 12431263. DOI: https://doi.org/10.1139/b04-123

576

577

578

579

580

581

582

583

584

585

Reed J., (2012). The effects of hemiparasitism by Castilleja species on community structure in alpine ecosystems. Pursuit-The Journal of Undergraduate Research at the University of Tennessee 3, no. 2: 8. Available at: http://trace.tennessee.edu/pursuit/vol3/iss2/8

Reid N., Yan Z., and Fittler J., (1994) Impact of mistletoes (Amyema miquelii) on host (Eucalyptus blakelyi and Eucalyptus melliodora) survival and growth in temperate Australia. Forest Ecology and Management,70, 55-65. DOI: https://doi.org/10.1016/0378-1127(94)90074-4

Salonen V., Vestberg M., and Vauhkonen M., (2001). The effect of host mycorrhizal status on host plant-parasitic plant interactions. Mycorrhiza 11, no. 2: 95-100. DOI: https://doi.org/10.1007/s005720100104 
586 Schmidt S. K., Sobieniak-Wiseman L. C., Kageyama S. A., Halloy S. R. P., and Schadt, C. W.,

587 (2008). Mycorrhizal and dark-septate fungi in plant roots above 4270 meters elevation in 588 the Andes and Rocky Mountains. Arctic, Antarctic, and Alpine Research, 40(3), pp.576-

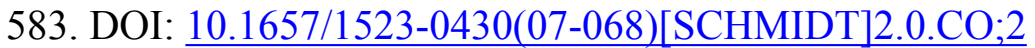

590

591

592

Spasojevic M. J., and Suding, K. N., (2012). Inferring community assembly mechanisms from functional diversity patterns: the importance of multiple assembly processes. Journal of Ecology, 100(3), 652-661. DOI: https://doi.org/10.1111/j.1365-2745.2011.01945.x

Smith S., and Read Q. D., (2008) Colonization of roots and anatomy of arbuscular mycorrhiza. Mycorrhizal Symbiosis. Academic Press: London: 42-90. DOI: 10.1371/journal.ppat. 1002600

Stein C., Rißmann C., Hempel S., Renker C., Buscot F., Prati D., and Auge H., (2009) Interactive effects of mycorrhizae and a root hemiparasite on plant community productivity and diversity. Oecologia 159, no. 1: 191-205. DOI: https://doi.org/10.1007/s00442-008-1192

Stewart R. G., and Press C. M., (1990). The physiology and biochemistry of parasitic angiosperms." Annual review of plant biology 41, no. 1: 127-151. DOI: https://doi.org/10.1146/annurev.pp.41.060190.0010152

Sundqvist M. K., Sanders N. J., and Wardle D. A., (2013). Community and ecosystem responses to elevational gradients: processes, mechanisms, and insights for global change. Annual Review of Ecology, Evolution, and Systematics, 44, 261-280.

Sweatt M. R., (1997). The effects of various host plants on growth, water relations, and carbon balance of the hemiparasite Castilleja indivisa [PhD thesis]. College Station (TX): Texas A\&M University. $92 \mathrm{p}$ 
609 Těšitel J., Lepš J., Vráblová M., and Cameron D.D., (2011). The role of heterotrophic carbon

610 acquisition by the hemiparasitic plant Rhinanthus alectorolophus in seedling

611 establishment in natural communities: a physiological perspective. $\mathrm{New}$

612 Phytologist, 192(1), pp.188-199. DOI: https://doi.org/10.1111/j.1469-8137.2011.03777.x

613 Těšitel J., Mládek J., Fajmon K., Blažek P., and Mudrák O., (2018). Reversing expansion of:

614 Hemiparasitic rhinanthus major does a better job than increased mowing intensity

615 Calamagrostis epigejos: Hemiparasitic Rhinanthus major does a better job than increased

616

617 mowing intensity in a grassland biodiversity hotspot: Hemiparasitic Rhinanthus major

618 does a better job than increased mowing intensity. Applied Vegetation Science, 21(1), pp. 104-112.

Těšitel J., Těšitelová T., Fisher J. P., Lepš J., and Cameron D. D., (2015). Integrating ecology and physiology of root-hemiparasitic interaction: interactive effects of abiotic resources

Usuki F., and Narisawa K., (2007). A mutualistic symbiosis between a dark septate endophytic fungus, Heteroconium chaetospira, and a nonmycorrhizal plant, Chinese cabbage. Mycologia 99, no. 2: 175-184. DOI: https://doi.org/10.1080/15572536.2007.11832577

626 Vergara C., Araujo K. E., Urquiaga S., Schultz N., Balieiro F. D. C., Medeiros P. S., and Zilli, J. E., (2017). Dark septate endophytic fungi help tomato to acquire nutrients from ground plant material. Frontiers in microbiology, 8, 2437. DOI: https://doi.org/10.3389/fmicb.2017.02437

630 Watson D. M., (2009). Parasitic plants as facilitators: more Dryad than Dracula?. Journal of 631 Ecology, 97(6), pp.1151-1159. DOI: https://doi.org/10.1111/j.1365-2745.2009.01576.x 
632 Westbury D. B., Davies A., Woodcock A. B., and Dunnett P. N., (2006) Seeds of change: the 633 value of using Rhinanthus minor in grassland restoration. Journal of Vegetation

634 Science 17, no. 4: 435-446. DOI: https://doi.org/10.1658/1100-

$635 \quad$ 9233(2006)17[435:SOCTVO]2.0.CO;2

636 Westbury D. B., and Dunnett N. P., (2007): The impact of Rhinanthus minor in newly

637 established meadows on a productive site. Applied Vegetation Science 10, no. 1 121-129.

638 DOI: https://doi.org/10.1111/j.1654-109X.2007.tb00510.x

639 Whittaker R. H., Bormann F. H., Likens G. E., Siccama T. G., (1974). The Hubbard Brook

640 ecosystem study: forest biomass and production. Ecol. Monogr. 44(2):233-54. DOI:

$641 \quad$ https://doi.org/10.2307/1942313

642 


\section{Figure Legends}

644

645 Figure 1: Plant richness and plant evenness (probability of interspecific encounter, PIE) within a $6460.5 \mathrm{~m} \times 0.5 \mathrm{~m}$ quadrat across five elevational sites with Castilleja present (blue) or Castilleja 647 absent (orange). Each boxplot consists of ten plots at each elevation site. The midline represents 648 the median value, with lower and upper hinges corresponding to the $25^{\text {th }}$ and $75^{\text {th }}$ percentiles. 649 The upper and lower whiskers extend from the hinges to highest to the lowest values but no 650 further than $1.5 \times$ the inter-quartile range (IQR).

651

652 Figure 2: Non-metric multidimensional scaling of plant community composition based on Bray653 Curtis distances with either Castilleja present (blue) or absent (orange) across 5 elevational sites. 654 Plant species identities: ACHMIL = Achillea millefolium, ADELEW = Adenolinum lewisii, 655 AGOGLA = Agoseris glauca, AGO_SP = Agoseris sp., ALLSEP = Allium sp., ANDSEP = 656 Androsace septentrionalis, ANTROS = Antennaria rosea, ARCUVA = Arctostaphylos uva-ursi, 657 ARNMOL $=$ Arnica mollis, ARTTRI $=$ Artemisia tridentate, $\mathrm{BALSAG}=$ Balsamorhiza 658 sagittata, BOESTR $=$ Boechera stricta, $\mathrm{BROINE}=$ Bromopsis inermis, $\mathrm{CAPBUR}=$ Capsella 659 bursa-pastoris, CARALB $=$ Carex albonigra, CAR_SP $=$ Carex sp., CHRVIS $=$ Chrysothamnus 660 viscidiflorus, CLATON = Claytonia lanceolata, DELNUT = Delphinium nuttallianum, 661 DRAAUR = Draba aurea, ELYELY = Elymus elymoides, ERECON = Eremogone congesta,

662 ERISPE $=$ Erigeron speciosus, ERI_SP = Erigeron sp., ERYGRA = Erythronium grandiflorum, 663 FESTHU $=$ Festuca thurberi, FRAVIR $=$ Fragaria virginiana, GALSEP $=$ Galium 664 septentrionale, HELQUI = Helianthella quinquenervis, $\mathrm{IPOAGG}=$ Ipomopsis aggregate, 665 JUNDRU = Juncus drummondii, LIGPOR = Ligusticum porteri, MAHAQU = Mahonia repens, 
666 MUHMON = Muhlenbergia montana, $\mathrm{PHASER}=$ Phacelia sericea, POA_SP $=$ Poa sp.,

667 PHLOX $=$ Phlox hoodii, POTGRA $=$ Potentilla gracilis, PSEMON $=$ Pseudocymopterus

668 montanus, PULPAT $=$ Pulsatilla patens, $\mathrm{ROSWOO}=$ Rosa woodsii, SEDLAN $=$ Sedum

669 lanceolatum, SENCRA = Senecio crassulus, SYMROT = Symphoricarpos rotundifolia,

670 TAROFF $=$ Taraxiacum officinale, THAFEN $=$ Thalictrum fendleri, VIOADU = Viola adunca.

671

672 Figure 3: Colonization rates of A) mycorrhizal fungi as either arbuscular mycorrhizal fungi 673 (AMF - at 2480m, 2740m, 3200m, 3392m, 3460m) or ericoid mycorrhizal fungi (ERM 674 3460m) and B) dark-septate endophytes (DSE) across all five elevational sites with Castilleja 675 present (blue) or Castilleja absent (orange). Each boxplot consists of ten plots at each elevation 676 site. The midline represents the median value, with lower and upper hinges corresponding to the $67725^{\text {th }}$ and $75^{\text {th }}$ percentiles. The upper and lower whiskers extend from the hinges to highest to the 678 lowest values but no further than $1.5 \times$ the inter-quartile range (IQR).

679

680 Table 1: Site characteristics, dominant plant species, functional group of the dominant species, 681 and root associated fungi within dominant plant roots. Elev = Elevation, MAT = mean annual 682 temperature, MAP = mean annual precipitation. $\mathrm{AMF}=$ arbuscular mycorrhizal fungi, $\mathrm{DSE}=$ 683 dark-septate endophytes, ERM = ericoid mycorrhizal fungi. 684

685 Table 2: Analysis of deviance table from "best-fit" mixed-model results exploring how site 686 (elevation), the presence of Castilleja (Castilleja present), and the interaction of elevation and 687 Castilleja presence on plant richness, plant evenness (probability of interspecific encounter, 688 PIE), mycorrhizal fungal colonization, and dark septate endophyte (DSE) colonization. Full 
689 model selection can be seen in Table S1. $\chi^{2}=$ chi squared value, $\mathrm{Df}=$ degrees of freedom, $P=\mathrm{p}$

690 value.

691

692 Table 3: Site-level (elevation) abundance-weighted PERMANOVA results to partition the effect 693 of Castilleja presence (Castilleja present) and spatial structure (plot pairing) on plant community 694 composition using Bray-Curtis distances. Df = degrees of freedom, SS = Sequential sums of 695 Squares, MeanSqs $=$ Mean squares, $F=F$ statistic, $\mathrm{R}^{2}=$ partial $\mathrm{R}^{2}, P=\mathrm{p}$ value.

696

697 Table S1: Model selection to determine "best" fit mixed model to predict plant richness, plant 698 evenness, mycorrhizal colonization, and dark septate endophyte colonization. Full mixed models 699 were constructed with Castilleja presence and elevation as fixed factors and intercepts were 700 allowed to vary by plot pairings (random effect). Fixed effects were sequentially removed from

701 the full model until we only fit the random effect. We report the number of model parameters 702 (df) and AIC score (AIC).

703

704 Table S2: PERMANOVA results to partition the effect of site (Elevation), Castilleja presence 705 (Castilleja present) and spatial structure (plot pairing) on plant community composition using 706 Bray-Curtis distances. Df = degrees of freedom, SS = Sequential sums of Squares, MeanSqs = 707 Mean squares, $F=F$ statistic, $\mathrm{R}^{2}=$ partial $\mathrm{R}^{2}, P=$ p value.

708

709 Table S3: Site level (elevation) PERMANOVA results to partition the effect of Castilleja

710 presence (Castilleja present) and spatial structure (plot pairing) on plant community composition 
711 using Jaccard's distances. $\mathrm{Df}=$ degrees of freedom, $\mathrm{SS}=$ Sequential sums of Squares, MeanSqs $712=$ Mean squares, $F=F$ statistic, $\mathrm{R}^{2}=$ partial $\mathrm{R}^{2}, P=\mathrm{p}$ value.

713 


\section{Figure 1}

Plant richness ( $A$ ) and plant evenness ( $B$, probability of interspecific encounter) within a $0.5 \mathrm{~m} \times 0.5 \mathrm{~m}$ quadrat across five elevational sites with Castilleja present (blue) or Castilleja absent (orange)

Each boxplot consists of ten plots at each elevation site. The midline represents the median value, with lower and upper hinges corresponding to the $25^{\text {th }}$ and $75^{\text {th }}$ percentiles. The upper and lower whiskers extend from the hinges to highest to the lowest values but no further than $1.5 \times$ the inter-quartile range (IQR). 

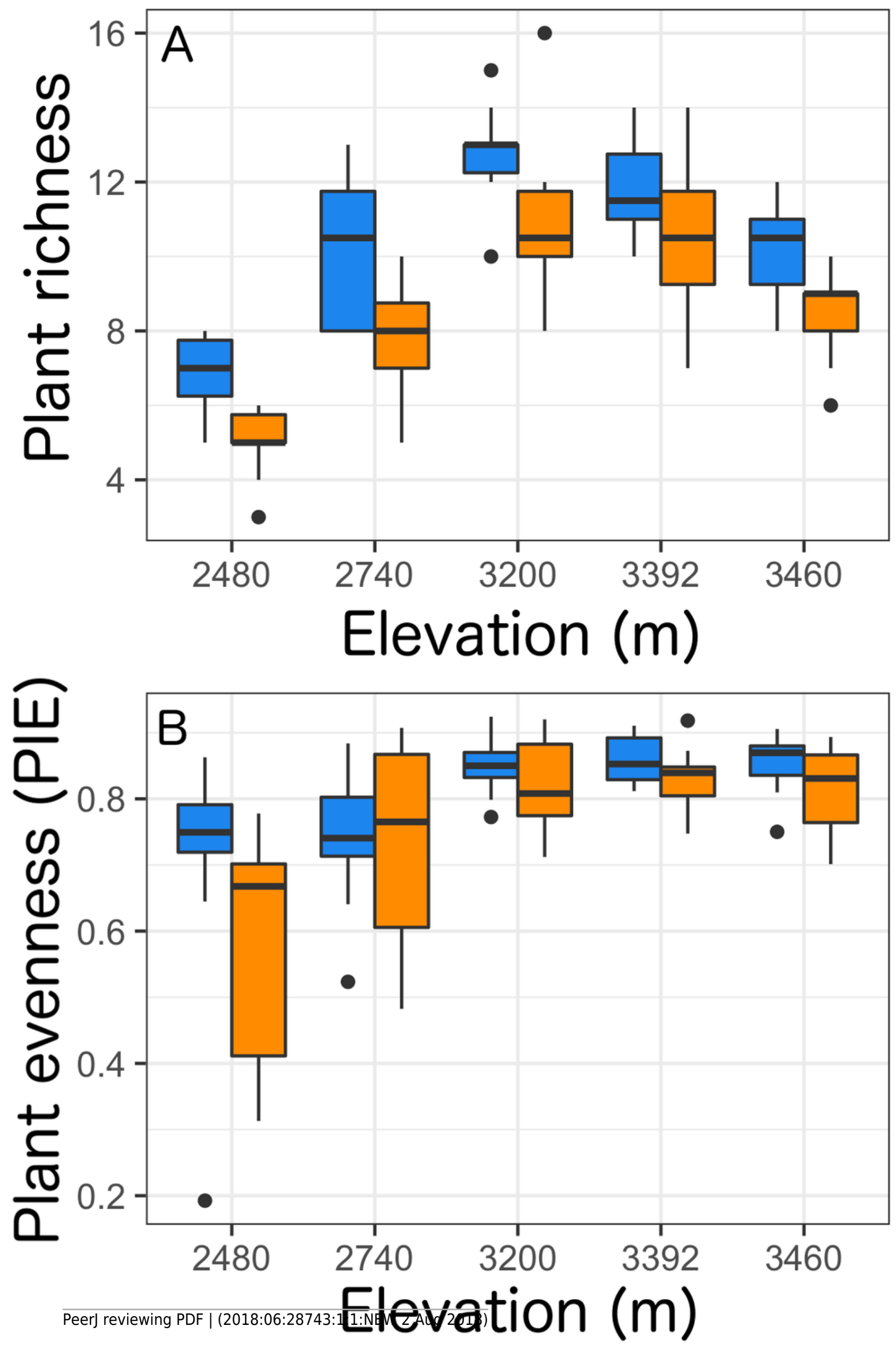


\section{Figure 2}

Non-metric multidimensional scaling of plant community composition based on BrayCurtis distances with either Castilleja present (blue) or absent (orange) across 5 elevational sites.

(A) 2480 m, (B) 2740 m, (C) 3200 m, (D) 3392 m, (E) 3460 m. Plant species identities: ACHMIL $=$ Achillea millefolium, $\mathrm{ADELEW}=$ Adenolinum lewisii, $\mathrm{AGOGLA}=$ Agoseris glauca, AGO_SP $=$ Agoseris sp., ALLSEP $=$ Allium sp., ANDSEP $=$ Androsace septentrionalis, ANTROS $=$ Antennaria rosea, $\mathrm{ARCUVA}=$ Arctostaphylos uva-ursi, $\mathrm{ARNMOL}=$ Arnica mollis, $\mathrm{ARTTR}=$ Artemisia tridentate, $\mathrm{BALSAG}=$ Balsamorhiza sagittata, BOESTR $=$ Boechera stricta, $\mathrm{BROINE}=$ Bromopsis inermis, CAPBUR = Capsella bursa-pastoris, CARALB $=$ Carex albonigra, CAR_SP $=$ Carex sp., CHRVIS = Chrysothamnus viscidiflorus, CLATON = Claytonia lanceolata, DELNUT $=$ Delphinium nuttallianum, DRAAUR = Draba aurea, ELYELY = Elymus elymoides, ERECON = Eremogone congesta, ERISPE = Erigeron speciosus, ERI_SP $=$ Erigeron sp., ERYGRA = Erythronium grandiflorum, FESTHU = Festuca thurberi, FRAVIR = Fragaria virginiana, GALSEP = Galium septentrionale, HELQUI = Helianthella quinquenervis, IPOAGG = Ipomopsis aggregate, JUNDRU = Juncus drummondii, LIGPOR = Ligusticum porteri, MAHAQU = Mahonia repens, $\mathrm{MUHMON}=$ Muhlenbergia montana, PHASER $=$ Phacelia sericea, POA_SP $=$ Poa sp., PHLOX $=$ Phlox hoodii, POTGRA $=$ Potentilla gracilis, PSEMON $=$ Pseudocymopterus montanus, PULPAT $=$ Pulsatilla patens, ROSWOO $=$ Rosa woodsii, SEDLAN $=$ Sedum lanceolatum, SENCRA = Senecio crassulus, SYMROT $=$ Symphoricarpos rotundifolia, TAROFF $=$ Taraxiacum officinale, THAFEN $=$ Thalictrum fendleri, VIOADU $=$ Viola adunca. 

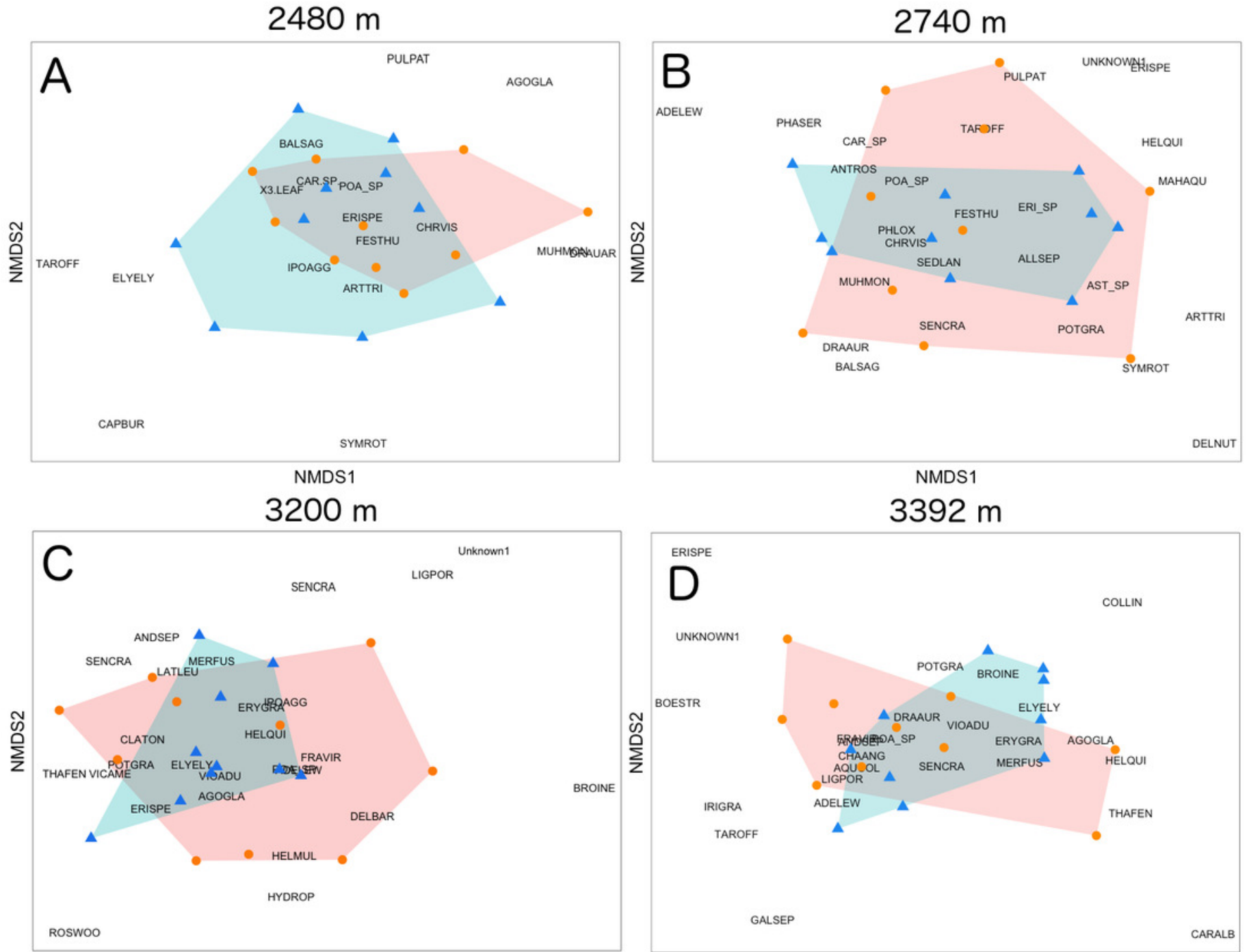

NMDS1
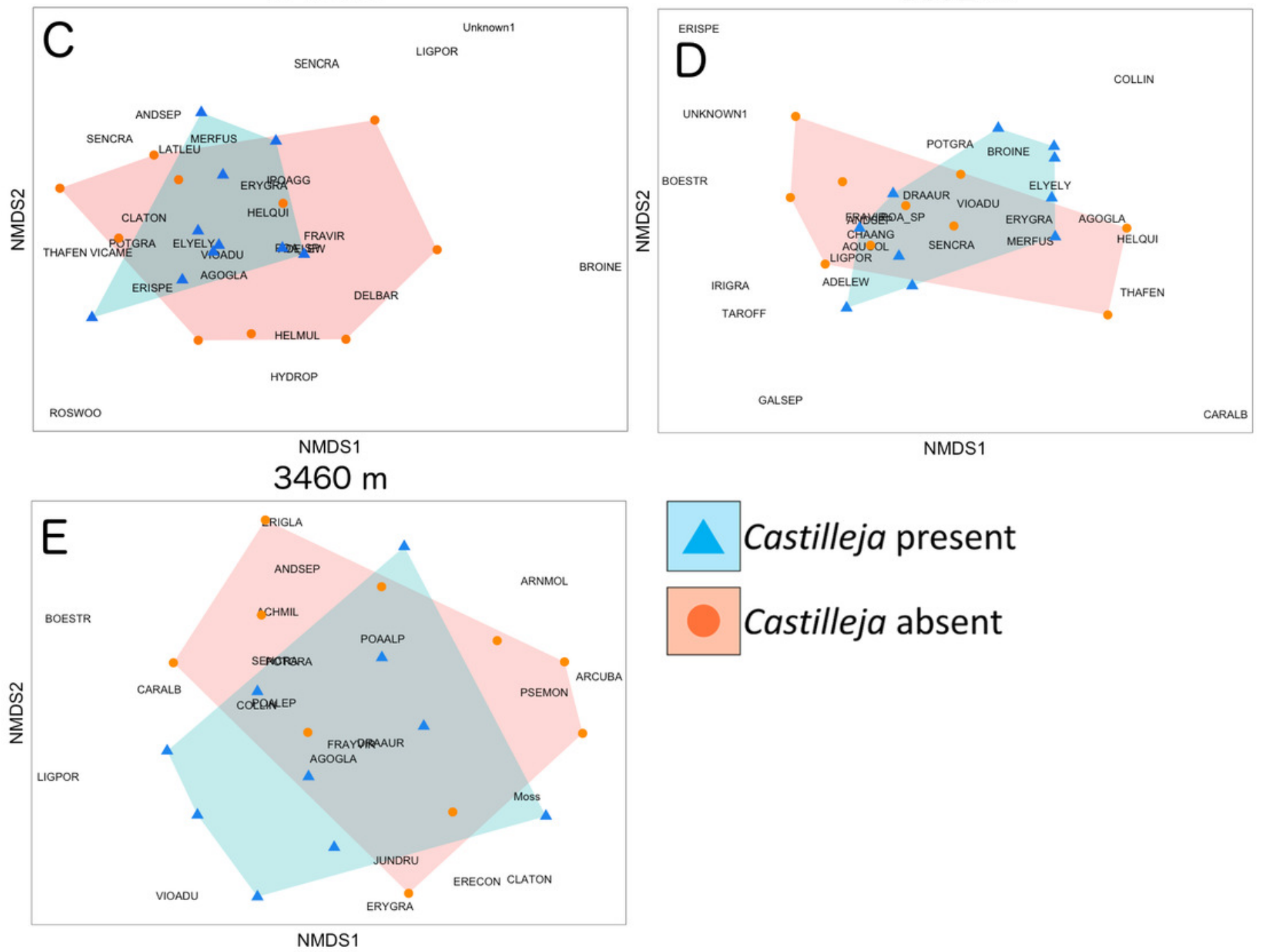


\section{Figure 3}

Colonization rates of (A) mycorrhizal fungi and (B) dark-septate endophytes (DSE) across all five elevational sites with Castilleja present (blue) or Castilleja absent (orange).

Mycorrhizal fungal colonization consists of arbuscular mycorrhizal fungi (AMF - at $2480 \mathrm{~m}$, 2740m, 3200m, 3392m, 3460m) or ericoid mycorrhizal fungi (ERM - 3460m). Each boxplot consists of ten plots at each elevation site. The midline represents the median value, with lower and upper hinges corresponding to the $25^{\text {th }}$ and $75^{\text {th }}$ percentiles. The upper and lower whiskers extend from the hinges to highest to the lowest values but no further than $1.5 \times$ the inter-quartile range (IQR). 

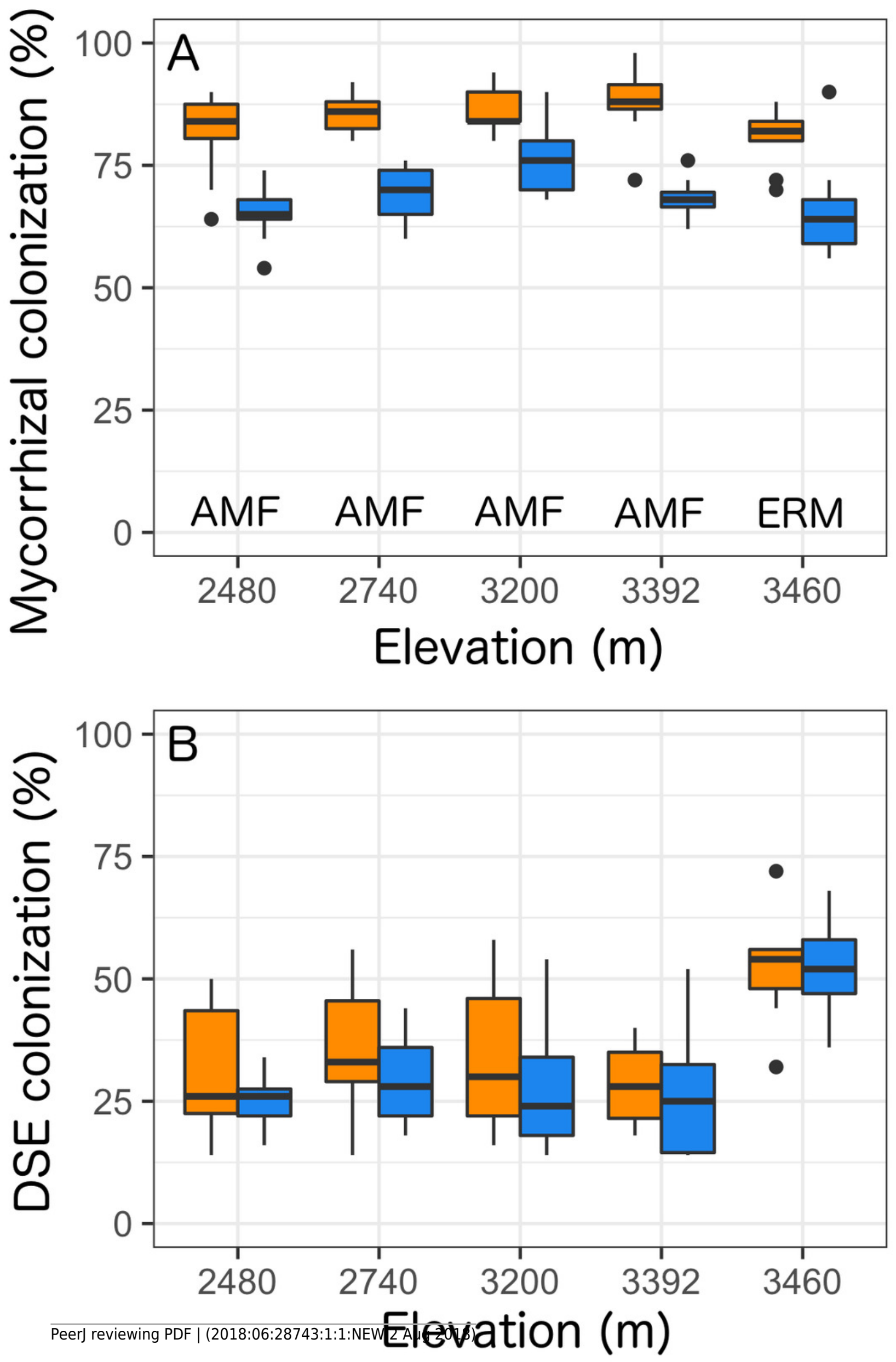


\section{Table $\mathbf{1}$ (on next page)}

Site characteristics, dominant plant species, functional group of the dominant species, and root associated fungi within dominant plant roots.

Elev $=$ Elevation, $\mathrm{MAT}=$ mean annual temperature, $\mathrm{MAP}=$ mean annual precipitation. $\mathrm{AMF}=$ arbuscular mycorrhizal fungi, DSE = dark-septate endophytes, ERM = ericoid mycorrhizal fungi. 
1 Table 1:

\begin{tabular}{lrrrrr}
\hline Elev (m) & $\mathbf{2 4 8 0}$ & $\mathbf{2 7 4 0}$ & $\mathbf{3 2 0 0}$ & $\mathbf{3 3 9 2}$ & $\mathbf{3 4 6 0}$ \\
\hline Latitude & 38.65391 & 38.71533 & 38.96133 & 38.97005 & 38.99158 \\
Longitude & -106.86198 & -106.82264 & -107.03147 & -107.03987 & -107.06656 \\
MAT (C) & 1.36 & 1.52 & -0.80 & -0.70 & -1.62 \\
MAP (mm) & 443.4 & 439.2 & 599.0 & 592.0 & 667.8 \\
$\begin{array}{c}\text { Castilleja sp } \\
\text { present }\end{array}$ & C. angustifolia & C. angustifolia & C. sulphurea & C. miniata & C. sulphurea \\
$\begin{array}{c}\text { Castilleja } \\
\text { cover (\%) }\end{array}$ & & & & C. sulphurea & C. m. -1.2 \\
$\begin{array}{c}\text { Targeted } \\
\text { species }\end{array}$ & Balsamorhiza & Chrysothamnus & Viola adunca & Ligusticum & Arctostaphylos \\
$\begin{array}{c}\text { Functional } \\
\text { group }\end{array}$ & sagittata & viscidiflorus & & porteri & uva-ursi \\
$\begin{array}{c}\text { Fungi } \\
\text { present }\end{array}$ & Forb & Forb & Forb & Forb & Shrub \\
\hline
\end{tabular}




\section{Table 2 (on next page)}

Analysis of deviance table from "best-fit" mixed-model results exploring how site, the presence of Castilleja, and the interaction influence plant richness, plant evenness, and fungal colonization.

Cast present $=$ presence of Castilleja, Sum Sq $=$ sum of squares, $\mathrm{Df}=$ Degrees of freedom, $F=F$ statistic, $P=P$ value. 
1 Table 2:

2

\begin{tabular}{llrrr}
\hline Response & Retained factors & $\chi^{2}$ & Df & $P$ \\
\hline Plant richness & Castilleja present & $\mathbf{5 2 . 3 6 0}$ & $\mathbf{1}$ & $<\mathbf{0 . 0 0 0 1}$ \\
& Elevation & $\mathbf{3 8 . 9 0 5}$ & $\mathbf{1}$ & $<\mathbf{0 . 0 0 0 1}$ \\
& Castilleja $\times$ Elevation & 0.4467 & 1 & 0.504 \\
& & & & \\
Plant evenness (PIE) & Castilleja present & $\mathbf{6 . 8 0 5 0}$ & $\mathbf{1}$ & $\mathbf{0 . 0 0 9}$ \\
& Elevation & $\mathbf{3 6 . 6 2 7}$ & $\mathbf{1}$ & $<\mathbf{0 . 0 0 0 1}$ \\
& Castilleja $\times$ Elevation & 1.5041 & 1 & 0.220 \\
Mycorrhizal colonization (\%) & Castilleja present & $\mathbf{1 6 3 . 1 7}$ & $\mathbf{1}$ & $<\mathbf{0 . 0 0 0 1}$ \\
DSE colonization $(\%)$ & Elevation & $\mathbf{1 1 . 4 9 7}$ & 1 & $\mathbf{0 . 0 0 0 7}$ \\
\hline
\end{tabular}

3 


\section{Table 3(on next page)}

Site-level (elevation) abundance-weighted (Bray-Curtis) PERMANOVA results to partition the effect of Castilleja presence and spatial structure (plot pairing) on plant community composition.

$\mathrm{Df}=$ degrees of freedom, $\mathrm{SS}=$ Sequential sums of Squares, MeanSqs $=$ Mean squares, $F=$ Fstatistic, $\mathrm{R}^{2}=$ partial $\mathrm{R}^{2}, P=\mathrm{p}$ value. 
1 Table 3:

2

\begin{tabular}{|c|c|c|c|c|c|c|c|}
\hline Elevation & Factor & Df & SS & MeanSqs & $F$ & $\mathrm{R}^{2}$ & $P$ \\
\hline \multirow[t]{5}{*}{$2480 m$} & Castilleja present & 1 & 0.211 & 0.21099 & 1.087 & 0.0529 & 0.37 \\
\hline & Plot pairing & 1 & 0.500 & 0.50037 & 2.577 & 0.1255 & 0.05 \\
\hline & Cas. present $\times$ Pairing & 1 & 0.170 & 0.16982 & 0.875 & 0.0426 & 0.54 \\
\hline & Residuals & 16 & 3.106 & 0.19414 & & 0.7790 & \\
\hline & Total & 19 & 3.987 & & & 1.0000 & \\
\hline \multirow[t]{5}{*}{$2740 m$} & Castilleja present & 1 & 0.291 & 0.29112 & 2.173 & 0.1004 & 0.03 \\
\hline & Plot pairing & 1 & 0.243 & 0.24259 & 1.811 & 0.0837 & 0.14 \\
\hline & Cas. present $\times$ Pairing & 1 & 0.222 & 0.22188 & 1.656 & 0.0765 & 0.09 \\
\hline & Residuals & 16 & 2.143 & 0.13397 & & 0.7394 & \\
\hline & Total & 19 & 2.899 & & & 1.0000 & \\
\hline \multirow[t]{5}{*}{$3200 \mathrm{~m}$} & Castilleja present & 1 & 0.481 & 0.48098 & 2.637 & 0.1257 & 0.01 \\
\hline & Plot pairing & 1 & 0.278 & 0.27842 & 1.527 & 0.0727 & 0.11 \\
\hline & Cas. present $\times$ Pairing & 1 & 0.150 & 0.14983 & 0.822 & 0.0391 & 0.55 \\
\hline & Residuals & 16 & 2.918 & 0.18237 & & 0.7624 & \\
\hline & Total & 19 & 3.827 & & & 1.0000 & \\
\hline \multirow[t]{5}{*}{$3392 \mathrm{~m}$} & Castilleja present & 1 & 0.101 & 0.10117 & 0.756 & 0.0355 & 0.69 \\
\hline & Plot pairing & 1 & 0.523 & 0.52344 & 3.911 & 0.1837 & 0.01 \\
\hline & Cas. present $\times$ Pairing & 1 & 0.084 & 0.08361 & 0.625 & 0.0293 & 0.76 \\
\hline & Residuals & 16 & 2.141 & 0.13382 & & 0.7514 & \\
\hline & Total & 19 & 2.849 & & & 1.0000 & \\
\hline \multirow[t]{5}{*}{$3460 \mathrm{~m}$} & Castilleja present & 1 & 0.229 & 0.22856 & 1.076 & 0.0536 & 0.37 \\
\hline & Plot pairing & 1 & 0.546 & 0.54636 & 2.573 & 0.1280 & 0.04 \\
\hline & Cas. present $\times$ Pairing & 1 & 0.094 & 0.09421 & 0.444 & 0.0221 & 0.90 \\
\hline & Residuals & 16 & 3.398 & 0.21239 & & 0.7963 & \\
\hline & Total & 19 & 4.267 & & & 1.0000 & \\
\hline
\end{tabular}

